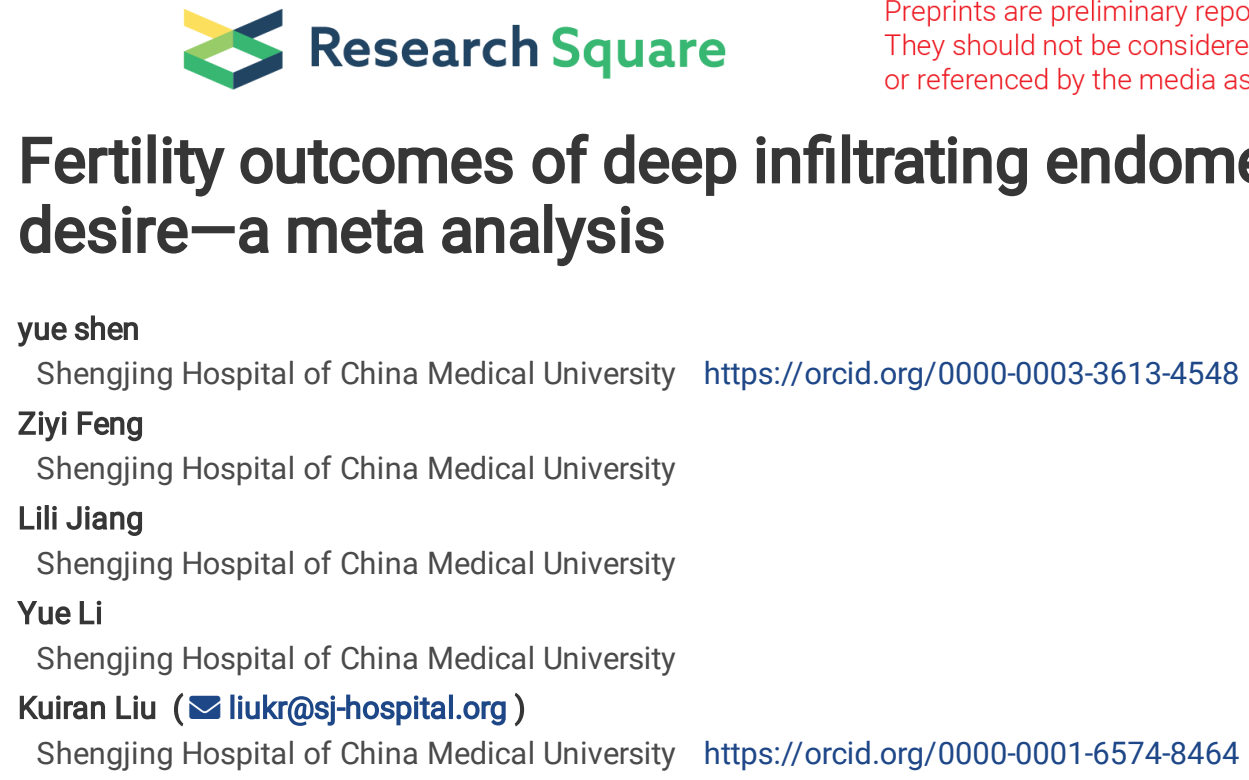

yue shen

Shengjing Hospital of China Medical University https://orcid.org/0000-0003-3613-4548

Ziyi Feng

Shengjing Hospital of China Medical University

Lili Jiang

Shengjing Hospital of China Medical University

Yue Li

Shengjing Hospital of China Medical University

Kuiran Liu ( $\square$ liukr@sj-hospital.org )

Shengjing Hospital of China Medical University https://orcid.org/0000-0001-6574-8464

\title{
Fertility outcomes of deep infiltrating endometriosis with fertility desire-a meta analysis
}

\section{Research article}

Keywords: deep infiltrating endometriosis; fertility desire; pregnant rates; assisted reproductive technology

Posted Date: January 20th, 2020

DOI: https://doi.org/10.21203/rs.2.21329/v1

License: @ (1) This work is licensed under a Creative Commons Attribution 4.0 International License. Read Full License 


\section{Abstract}

Background: The morbidity of endometriosis has been ascending in recent years. Deep infiltrating endometriosis is the most advanced type of endometriosis. The treatments for patients with DIE and fertility desire are controversial. Materials and Methods: We had search Pubmed, OVID Medline, Cochrane Library published before 2019-10-31, According to the inclusion criteria and exclusion criteria, a total of 17 articles were selected. A 95\% confidence interval (Cl) was used for clinical pregnancy data, and a random-effect model was used for meta-analysis. Subgroup analysis and sensitivity analysis were performed using Review manager 5.3. Results: Among patients with fertility desire, 370/1142 $(32.40 \%)$ conceived spontaneously after surgery, compared with 306/1108(27.62\%) got pregnant after surgery and assisted reproductive

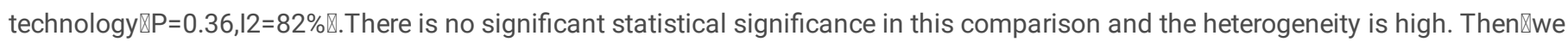
performed subgroup analysis and found that the heterogeneity was not caused by fertility status , surgical methods or study characteristics. Conclusion: Through this meta-analysis, we think that surgery combined ART or not doesn't effect on pregnancy rate in patients with DIE. But further investigations are required to determine fertility outcomes according to age, endometrioma, adenomyosis, ASRM scores and so on.

\section{Background}

Endometriosis is a benign disease which also has malignant potential. It is estimated that $10-15$ percent women were troubled by it ${ }^{[1]}$. And in recent years, the morbidity has been ascending. There are four types have been described: peritoneal endometriosis, ovarian endometriosis, deep infiltrating endometriosis (DIE) and others. And DIE is the most advanced type of it ${ }^{[2]}$. DIE was defined by the European Society of Human Reproduction and Embryology (ESHRE) as the infiltration of endometriosis-like tissue by more than $5 \mathrm{~mm}$ beneath the peritoneal ${ }^{[3]}$. In clinical work, we found that women with DIE have several symptoms, such as progressive dysmenorrhea, diarrhea, constipation, dysuria, dyspareunia and infertility .

We defined infertility as couples who doesn't get pregnant with normal sex life and without any contraception over a year. Endometriosisassociated infertility was first proposed by Buyalos ${ }^{[4]}$ in 2000 , and he mentioned that endometriosis interacted with infertility and had a big influence on the each part of pregnancy. In addition, infertility is a high risk for endometriosis. But there isn't exact association with DIE and infertility because of the coexistence of DIE and emdometrioma or adenomyosis. In fact, many patients with DIE in gestation age are complaining about infertility.

Up to now, the treatment of DIE with fertility desire has been controversial. Radical surgery, including colorectal resection, ureter resection, vaginal excision and so on, is considered as an infertility-enhanced management. And radical operation is associated with a higher risk of complications after surgery. And some researchers proposed less invasive operation (eg. rectovaginal shaving, rectal disc excision). In addition, other authors consider assist reproduction techniques as the best option. There isn't any randomized controls study about which one is the best procedure for infertility-age women with DIE up to date. This review is aim to found which is more appropriate, spontaneous pregnancy after surgery or assisted reproduction after surgery, for patients with DIE and pregnant wishes through meta-analysis.

\section{Methods}

This review was strictly followed the PRISMA guidelines ${ }^{[5]}$ for systematic reviews and our aim was to compare the pregnancy rates among patients with DIE and pregnant wishes who undergo surgery with ART or not. We had search Pubmed, OVID Medline, Cochrane Library published before 2019-10-31, using the key words 'DIE' ' deep endometriosis ' 'colorectal endometriosis' ' rectovaginal endometriosis"bowel endometriosis ' 'bladder endometriosis' 'ureter endometriosis" in vitro fertilization" assisted reproductive techniques ' 'medically assisted reproduction' 'surgery' 'spontaneous pregnancy' ' fertility'. And literatures published in English will be adopted. And our search strategy in Pubmed is: (((((deep infiltrating endometriosis[Title/Abstract]) OR deep endometriosis) OR deep infiltration endometriosis) OR colorectal endometriosis) OR rectovaginal endometriosis) OR bowel endometriosis) AND (((in vitro fertilization) OR assisted reproductive techniques) OR medically assisted reproduction) OR spontaneous pregnancy) AND English[lang]) AND surgery. All published literatures and their references have been reviewed systematically. We haven't attempt to look through unpublished articles.

\subsection{Study Selection}

Two authors screened the database independently to select articles which meet the inclusion criteria. Our inclusion criteria are as follows: 1 . Patients still have fertility requirements after surgery;2. The patients are in gestational age and the average age of the selected articles is not over 40 years;3. With the exception of RCT, included studies should be rated higher than 6 points by the Newcastle-Ottawa scale ${ }^{[6]} ; 4$. The method of pregnancy was recorded in detail; 5 . The mean follow-up time for all articles should be greater than 12 months. Exclusion criteria includes:1. If the distribution of pregnancies resulting from spontaneous attempts and from IVF/ICSI could not be discriminated between the two study groups, both types of conception were excluded in the analyses.2. The study sample size was smaller than 30;3. Patients with the same patient population in both articles with shorter follow-up time were excluded. 


\subsection{Data extraction}

We record the year of publication, research design, sample size and length of follow up. These are recorded in table 1. The Newcastle-Ottawa scale ${ }^{[6]}$ is used to evaluate the study qualities when the study type is a cohort study or a case-control study. The scale consists of three parts: selection of participants, comparability of groups and assessment of exposure. The quantitative appraisal of quality of Individual studies ranged from 0 to 9 . And all the articles involved in this study were greater than or equal to 6 . And we used Jadad scale to evaluate the quality of RCT. Randomization, double blinding, withdrawls and dropouts are used as a rating scale. 3-5 scores will be regard as high quality studies $^{[7]}$.

The rate of pregnant were obtained from individual reports. The pregnancy rate was separately determined in women with surgery or surgery and ART. The two observers independently evaluated all articles and abstracted data onto standardized forms. A final extraction form was compiled from the two evaluation forms, with correction or resolution of any discrepancies between reviewers by consensus reached after discussion or arbitration by a third reviewer.

\subsection{Data analysis}

A 95\% confidence interval (Cl) was used for clinical pregnancy data, and a random-effect model was used for meta-analysis ${ }^{[8]}$. The $\mathrm{I}^{2}$ statistics, which describe the proportion of the total variation of estimates across studies due to heterogeneity rather than chance, was then calculated. Negative values of $\mathrm{I}^{2}$ are set equal to 0 so that $\mathrm{I}^{2}$ lies between $0 \%$ and $100 \%$. A value of $0 \%$ indicates no observed heterogeneity, whereas $\mathrm{I}^{2}$ values of $25 \%, 50 \%$ and $75 \%$ indicate low, moderate and high heterogeneity, respectively ${ }^{[9]}$. A funnel plot ${ }^{[10]}$, was generated and visually inspected for asymmetry to determine if the included studies were nonrepresentative of the body of possible studies on the subject (which could result from small study effect or other biases, such as publication and poor-quality bias). Due to the high heterogeneity of the study results, we further conducted subgroup analysis according to the patients' age, region, infertility, surgical approaches and study characterics. Since we did not find the reason for the heterogeneity, we did further sensitivity analysis. Subgroup analysis and sensitivity analysis were performed using Review manager 5.3.

\section{Results}

Eventually, 17 articles ${ }^{[11-27]}$ were included in our study, 1 wasRCT,7 were prospective cohort studies and the others were retrospective. At the beginning, 153 studies were found in PUBMED $₫ 163$ studies in MEDLINE and 227 studies in Cocharane Library. 27 literatures were left after reading the abstracts and 17 full-text articles were selected for a meta-analysis(Table 2). The quality score of the cohort studies ranged from 7 to 8 and the RCT scores 4 (Table 3 )

A total of 1172 women with DIE desiring pregnancy,370/1142 (32.40\%) conceived spontaneously after surgery, compared with $306 / 1108(27.62 \%)$ got pregnant after surgery and $A R T \otimes P=0.36,12=82 \%$,Figure $1 区$

Funnel plots will be appropriate only the included papers larger than 10. Funnel plot is showed in Figure 2.

Because of the high heterogeneity of these studies, we performed subgroup analysis to find out why. We performed subgroup analysis according to different surgery methods, study characterics, patients' ages and patients' region. Unfortunately, we did not find the cause of heterogeneity through these subgroup analyses. We selected the results of two subgroup analyses and the results are shown in Figure 3 and Figure 4. As shown in Figure 3, we conclude that different surgery menthod is a reason caused high heterogeneity, but in three subgroups , there is still very high heterogeneity. In Figure 4, we don't think different study characterics can cause the heterogeneity.

The subgroup analysis did not account for the high heterogeneity of the study, so we excluded studies that fell outside the $95 \%$ confidence interval for sensitivity analysis in funnel plots. And result is shown in Figure 5.

\section{Discussion}

In this article, a total of 17 articles were included to compare the pregnancy rates of surgical patients with DIE who had fertility desire. Among them, 370/1142 (32.40\%) conceived spontaneously after surgery, compared with 306/1108(27.62\%) got pregnant after surgery and ART $\triangle \mathrm{P}=0.36,12=82 \% \bigotimes$. The results showed that the spontaneous pregnancy rate and assisted reproductive pregnancy rate after surgery were not statistically significant. In other words, for patients who have pregnant desires with DIE, spontaneous pregnancy and assisted reproductive pregnancy play the same role.

It is controversial that which is the best option for the patients with DIE and infertility until now. Some surgeons consider surgery as an enhanced-fertility treatment. Daraï $\mathrm{E}^{[28]}$ published the first randomized controlled experiment on the therapeutic effect of laparoscopic and 
open bowel resection for intestinal endometriosis. This study demonstrated that laparoscopy can provide patients with a higher pregnancy rate. Touboul, Cyril ${ }^{[29]}$ also believe that laparoscopy can improve postoperative pregnancy rate of patients, but most patients have a successful pregnancy within 2 years after surgery. Many professors believe that surgery combined with ART can be the first choice for patients. Ballester, Marcos ${ }^{[30]}$ analyzed the clinical data of 60 patients with DIE receiving ART after surgery. Studies have shown that the cumulative pregnancy rate after three embryo transfers can be as high as $78.1 \%$. Bendifallah $\mathrm{S}^{[31]}$ didn't agree with the views of the above professors. This article compares the spontaneous pregnancy rate and the pregnancy rate after assisted reproduction in patients with DIE, which is contrary to the results of the above studies. The reasons may be as follows: First, it was mentioned in the included studies that some patients had experienced assisted reproduction failure before surgery, and these patients would inevitably reduce the pregnancy rate in the surgery and assisted reproductive technology group. However, these patients also provide us with a little hope that if assisted reproductive technology fails in patients with DIE who have fertility desire, they can undergo surgery before assisted reproductive technology again. Second, some influencing factors, such as ASRM grade, adenomyosis or endometrioma, cannot be excluded in this paper. These factors may affect the pregnancy rate of patients.

Others believe that postoperative complications may delay the time of pregnancy, so ART is more effective. Mathieu D'Argent ${ }^{[32]}$ agree that women with colorectal endometriosis and a desire to become pregnant should be encouraged to consider IVF before undergoing colorectal resection. This paper only compared the pregnancy rates of postoperative spontaneous and postoperative assisted reproduction, because only two papers compared the pregnancy rates of direct surgery and direct assisted reproduction in the process of literature retrieval, which could not be further analyzed. It is controversial that which is the best option, surgery or assisted reproduction. On the one hand, the negative effect of surgery on ovarian function cannot be determined. On the other hand, postoperative complications affect the timing of pregnancy.

But the heterogeneity of this result is very high. So we wanted to determine the source of heterogeneity by subgroup analysis. There were four subgroups according to different surgical procedures, shaving, resection and others (Figure 3 , Inter-group $\left.\right|^{2}>50$, intra-group $\left.\right|^{2}>50$ ). Although different surgical procedures were the cause of heterogeneity, intra-group heterogeneity still existed, indicating that there were other reasons in this review. We can also see that there is only one article in the shaving group, so the result is inconsistent with our overall results. For patients undergoing shaving, the rate of assisted reproductive pregnancy is higher after surgery. Noémie Marty ${ }^{[25]}$ thought patients who underwent shaving had small lesion area, shallow infiltration depth and low postoperative complication rate. But we need higher quality, larger sample studies to confirm this. The last two sets of data are consistent with our previous results. Subgroup analysis was performed according to study characterics again (Figure 4, Inter-group $\mathrm{I}^{2}=0$, intra-group $\mathrm{I}^{2}>50$ ). We can clearly see that different subgroups can still reach the same conclusion as before, that is, there is no significant statistical difference between postoperative spontaneous pregnancy rate and postoperative assisted reproductive pregnancy rate. And we found that this is not the reason for the heterogeneity of the study. In addition, other subgroup analyses we conducted showed that the average age of patients, the location of patients and whether patients were infertile or not were not the reasons for the heterogeneity of the articles.

Sensitivity analysis was also performed to explain the source of heterogeneity. Using the funnel plot, we excluded the studies falling within and outside the $95 \%$ confidence interval boundary, and we re-analyzed the remaining studies (Figure $5, I^{2}=17, P=0.21$ ). After sensitivity analysis, heterogeneity decreased significantly and the results were consistent with the previous results which indicates that the results of this meta-analysis are robust. There is no statistical significance between postoperative spontaneous pregnancy rate and postoperative assisted reproductive pregnancy rate. That means there is no significant difference between postoperative spontaneous pregnancy and assisted reproductive pregnancy for DIE patients with fertility desire.

There are some limination in our review. First, in this review, subgroup analysis could not be conducted strictly according to whether the patients were infertile or not. Some of the studies included both infertile and fertile patients. Although we did a subgroup analysis, we learned that some of the patients who were not proved infertile were sterile. In addition, there are many factors that affect the infertility of patients with DIE, such as endometrioma, adenomyosis, preoperative infertility history, age and so on. Daraï E ${ }^{[15]}$ run a prospevtive study and proved that adenomyosis, patient age, ASRM score appeared determinant factors of fertility outcome. Nevertheless, Younis ${ }^{\text {[33] }}$ published a multivariate score to predict PRs in women with infertility and showed that the duration of infertility was a determinant factor especially when lasting more than 10 years. However, due to the limit data in this meta-anaysis included in the literature, further analysis of these factors was not possible.

The conclusions of this study should be treated with caution. In addition, some patients with pain symptoms mainly, if not surgical treatment, may be waiting for pregnancy symptoms increased unbearable may. We can only hope for more high-quality studies comparing pregnancy rates between the two methods. In addition, some scholars believe that expectant treatment is feasible. In this search, two studies ${ }^{\text {[34,35] }}$ compared the pregnancy rate of surgery and expectant treatment, and the results were inconsistent. A large number of high-quality studies are needed to conduct a meta-analysis. Last but not least, the studies we chosed in this review only consist of one RCT, and after sensitivity analysis we exclude it. We still need a large quantity of high-quality literature to prove our point. 


\section{Conclusions}

In conclusion, through this meta-analysis, we think surgery combined ART or not may provide a good option for patients with DIE. For whether or not to carry out assisted reproductive treatment, gynecological experts need to provide individual treatment according to patient's characterics. And further investigations are required to determine fertility outcomes according to age, endometrioma, adenomyosis, ASRM score and so on.

\section{Abbreviations}

deep infiltrating endometriosis :DIE

\section{Declarations}

Funding: Clincal Medicine Peak Supporting Program of China Medical University(2018, Gynecology)

Competing Interests: Author Yue Shen declares that she has no conflict of interest. Author Ziyi Feng declares that she has no conflict of interest. Author Lili Jiang declares that she has no conflict of interest. Author Yue Li declares that she has no conflict of interest. Author Kuiran Liu declares that she has no conflict of interest.

Ethical approval: This article does not contain any studies with human participants performed by any of the authors.

Consent for publication: Not Applicable

Availability of data and materials: All data generated or analysed during this study are included in this published article

Acknowledgements: We thank the China Medical University for their supporting

Ethics approval and consent to participate: Not Applicable

\section{Author Contribution List}

Conceptualization: Y Shen, ZY Feng, KR Liu

Data curation: Y Shen, LL Jiang

Formal analysis: Y Shen, LL Jiang

Investigation: Y Shen, ZY Feng, KR Liu

Methodology: Y Shen, ZY Feng, Y Li, KR Liu,

Validation: Y Shen, Y Li, KR Liu

Writing - original draft: Y Shen, Y Li, KR Liu

Writing - review \& editing: Yue Shen, LL Jiang, Kuiran Liu

\section{References}

[1]J. Julie Kim,Takeshi Kurita,Serdar E. Bulun. Progesterone Action in Endometrial Cancer, Endometriosis, Uterine Fibroids, and Breast Cancer[J]. Endocrine Reviews,2013,34(1)

[2]Schindler AE. Pathophysiology, diagnosis and treatment of endometriosis. Minerva Ginecol 2004;56:419-35.

[3]Dunselman GaJ, Vermeulen N, Becker C,et al. ESHRE guideline: management of women with endometriosis. Hum Reprod Oxf Engl. 2014;29:400-12.

[4]Buyalos RP, Agarwal SK,et al. Endometriosis-associated infertility. Curr Opin Obstet Gynecol. 2000 ,12(5):377-381

[5]Moher, D., Liberati, A., Tetzlaff, J., Altman, D.G.PRISMA Group, 2009. Preferred reporting items for systematic reviews and meta-analyses: the PRISMA statement. Ann. Int. Med. 151, 264-269. 
[6]Wells, G.A., Shea, B., O’Connell, D., Peterson, J., Welch, V., Tugwell, P., 2000. The Newcastle-Ottawa Scale (NOS) for assessing the quality of nonrandomized studies in meta-analyses. 3rd Symposium on Systematic Reviews: Beyond the Basics, Oxford, U.K. Available from: <http://www.ohri.ca/programs/ clinical_epidemiology/oxford.htm>.

[7]Jadad AR, Moore RA, Carroll D. Assessing the quality of reports of randomized clinical trials: is blinding necessary? Control Clin Trials $1996 ; 17: 1-12$

[8]Egger, M., Davey, S.G., Altman, D.G., 2001. Systematic Reviews in Health Care: Meta-Analysis in Context, Part IV, second ed. BMJ Publishing Group, pp. 285-312 (Chapters 15-16).

[9]BMJ 327, 557-560.

[10]Egger, M., Smith, G.D., Phillips, A.N., 1997. Meta-analysis: principles and procedures. BMJ 315, 1533-1537.

[11] Stepniewska A, Pomini P, Bruni F, et al. Laparoscopic treatment of bowel endometriosis in infertile women. Hum Reprod. 2009;24(7):16191625. doi:10.1093/humrep/dep083

[12] Abo C, Stochino-loi E, Merlot B, Moatassim-drissa S, Roman H. Surgery for deep endometriosis without involvement of digestive or urinary tracts: do not worry the patients! doi:10.1016/j.fertnstert.2018.02.124

[13] Meuleman C, Tomassetti C, Hoore AD, et al. Clinical outcome after CO 2 laser laparoscopic radical excision of endometriosis with colorectal wall invasion combined with laparoscopic segmental bowel resection and reanastomosis. 2011;26(9):2336-2343.

doi:10.1093/humrep/der231

[14]Meuleman C, Tomassetti C, Wolthuis A, et al. Clinical Outcome After Radical Excision of Moderate-Severe Endometriosis With or Without Bowel Resection and Reanastomosis. Ann Surg. 2014;259(3):522-531. doi:10.1097/SLA.0b013e31828dfc5c

[15] Daraï E, Carbonnel M, Dubernard G, et al. Determinant factors of fertility outcomes after laparoscopic colorectal resection for endometriosis. Eur J Obstet Gynecol Reprod Biol. 2010;149(2):210-214. doi:10.1016/j.ejogrb.2009.12.032

[16] Centini G, Afors K, Murtada R, et al. Impact of Laparoscopic Surgical Management of Deep Endometriosis on Pregnancy Rate. J Minim Invasive Gynecol. 2016;23(1):113-119. doi:10.1016/j.jmig.2015.09.015

[17] Centini G, Afors K, Alves J. Effect of Anterior Compartment Endometriosis Excision on Infertility. 2018;22(4). doi:10.4293/JSLS.2018.00067

[18] Aas-eng K, Birsan T, Berger F, et al. Pain and fertility outcomes of nerve-sparing, full-thickness disc or segmental bowel resection for deep infiltrating endometriosis (DIE) - a prospective cohort study. :0-3. doi:10.1111/aogs.13436

[19] Roman H, Quibel S, Auber M, et al. Recurrences and fertility after endometrioma ablation in women with and without colorectal endometriosis: A prospective cohort study. Hum Reprod. 2015;30(3):558-568. doi:10.1093/humrep/deu354

[20] Roman $\mathrm{H}$, Chanavaz-lacheray I, Ballester $\mathrm{M}$, et al. High postoperative fertility rate following surgical management of colorectal endometriosis. 2018;(July):1-8. doi:10.1093/humrep/dey146

[21] Luca Minelli, MD;Francesco Fanfani, MD, et al.Objective:Toevaluatetheshort-andlong-termoutcomesOutcome C. Laparoscopic Colorectal Resection for Bowel Endometriosis. 2009;144(3):234-239.

[22] Blanc M, von Theobald P. Fertility after surgery for deep infiltrating endometriosis. J Gynecol Obstet Hum Reprod. 2017;46(2):143-146. doi:10.1016/j.jogoh.2016.12.005

[23] Malzoni M, Giovanni A Di, Exacoustos C, et al. Laparoscopic Assisted Bowel Segmental Resection for Deep Infiltrating Endometriosis Feasibility and Safety: A Retrospective Cohort Study with Description of Technique. J Minim Invasive Gynecol. 2015.

doi:10.1016/j.jmig.2015.09.024

[24] Nicolas Bourdel, Aurélie Comptour, Paméla Bouchet, et al.Long-term evaluation of painful symptoms and fertility after surgery for large rectovaginal endometriosis nodule: a retrospective study. doi: 10.1111/aogs.13260

[25]Marty N, Touleimat S, Moatassim-drissa S, et al. Rectal Shaving Using Plasma Energy in Deep Infiltrating Endometriosis of the Rectum: Four Years of Experience. J Minim Invasive Gynecol. 2018;24(7):1121-1127. doi:10.1016/j.jmig.2017.06.019

Page 6/10 
[26]Camerini G, Remorgida V, D M. Fertility after bowel resection for endometriosis. Fertil Steril. 2009;92(1):41-46.

doi:10.1016/j.fertnstert.2008.04.070

[27] Kishi Y, Yabuta M. The benefit of adenomyomectomy on fertility outcomes in women with rectovaginal endometriosis with coexisting adenomyosis. Gynecol Minim Invasive Ther. 2016. doi:10.1016/j.gmit.2016.08.002

[28] Daraï E, Dubernard G, Coutant C, Frey C, Rouzier R, Ballester M. Randomized Trial of Laparoscopically Assisted Versus Open Colorectal Resection for Endometriosis. Ann Surg. 2010;251(6):1018-1023. doi:10.1097/SLA.0b013e3181d9691d

[29]Touboul C, Ballester M, Dubernard G, Zilberman S, Thomin A, Daraï E. Long-term symptoms, quality of life, and fertility after colorectal resection for endometriosis: extended analysis of a randomized controlled trial comparing laparoscopically assisted to open surgery. Surg Endosc Other Interv Tech. 2015;29(7):1879-1887. doi:10.1007/s00464-014-3880-4

[30] Ballester M, Roman H, Mathieu E, Touleimat S, Belghiti J, Daraï E. Prior colorectal surgery for endometriosis-associated infertility improves ICSI-IVF outcomes: results from two expert centres. Eur J Obstet Gynecol Reprod Biol. 2017;209:95-99.

doi:10.1016/j.ejogrb.2016.02.020

[31]Bendifallah S, Roman H, Mathieu d'Argent E, et al. Colorectal endometriosis-associated infertility: should surgery precede ART? Fertil Steril. 2017;108(3):525-531.e4. doi:10.1016/j.fertnstert.2017.07.002

[32]Mathieu D'Argent E, Coutant C, Ballester M, et al. Results of first in vitro fertilization cycle in women with colorectal endometriosis compared with those with tubal or male factor infertility. Fertil Steril. 2010;94(6):2441-2443. doi:10.1016/j.fertnstert.2010.03.033

[33] Younis JS, Jadaon J, Izhaki I, Haddad S, Radin O, Bar-Ami S, et al. A simple multivariate score could predict ovarian reserve, aswell as pregnancy rate, in infertile women. Fertil Steril. 2009 Apr 13.

[34]Vercellini P, Pietropaolo G, De Giorgi O, Daguati R, Pasin R, Crosignani PG. Reproductive performance in infertile women with rectovaginal endometriosis: Is surgery worthwhile? Am J Obstet Gynecol. 2006;195(5):1303-1310. doi:10.1016/j.ajog.2006.03.068

[35] Leone Roberti Maggiore U, Scala C, Tafi E, et al. Spontaneous fertility after expectant or surgical management of rectovaginal endometriosis in women with or without ovarian endometrioma: a retrospective analysis. Fertil Steril. 2017;107(4):969-976.e5. doi:10.1016/j.fertnstert.2017.02.106

\section{Tables}

Table1. Basic characterics of studies

\begin{tabular}{|c|c|c|c|c|}
\hline & year of publication & study characteristics & number & length of follow up $\llbracket$ months $\square$ \\
\hline A. Stepniewska2009 & 2009 & prospective cohort & 94 & 26.9 \\
\hline Aurélie Vallée 2018 & 2018 & retrospective cohort & 52 & 45.9 \\
\hline Christel Meuleman2009 & 2009 & retrospective cohort & 33 & 29 \\
\hline Christel Meuleman2014 & 2014 & prospective cohort & 54 & 27 \\
\hline Emile Daraï, 2010 & 2010 & prospective cohort & 51 & 34 \\
\hline Gabriele Centini2016 & 2016 & retrospective cohort & 115 & 22 \\
\hline Gabriele Centini2018 & 2018 & retrospective cohort & 55 & 24 \\
\hline Gernot Hudelist2018 & 2018 & prospective cohort & 61 & 34.3 \\
\hline Horace Roman2015 & 2015 & prospective cohort & 38 & 32 \\
\hline Horace Roman2018 & 2018 & $\mathrm{RCT}$ & 36 & $50-79$ \\
\hline Luca Minelli2009 & 2009 & prospective cohort & 113 & 19.6 \\
\hline M.Blanc 2017 & 2017 & retrospective cohort & 63 & 14.2 \\
\hline Mario Malzoni2015 & 2015 & retrospective cohort & 72 & 12 \\
\hline Nicolas Bourdel2018 & 2018 & retrospective cohort & 138 & 60 \\
\hline Noémie Marty 2017 & 2017 & retrospective cohort & 32 & 36 \\
\hline Simone Ferrero2009 & 2009 & prospective cohort & 46 & 49.9 \\
\hline Yohei Kishi 2016 & 2016 & retrospective cohort & 119 & 24 \\
\hline
\end{tabular}

Due to technical limitations Table 2 is available as a download in the Supplementary Files.

Table 3. Quality assessment of the include studies 


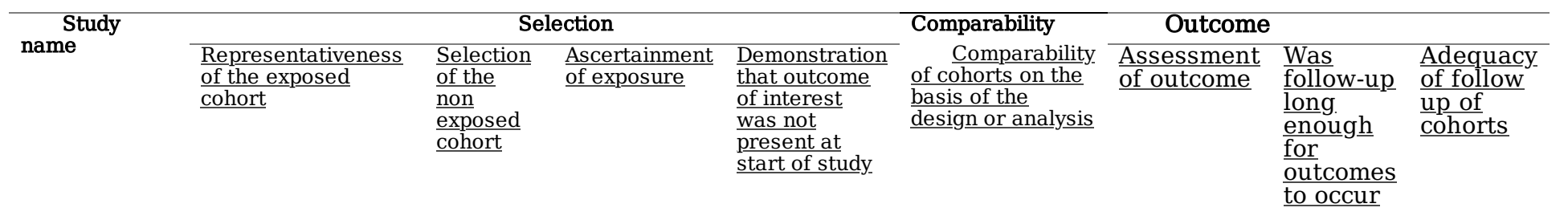

\begin{tabular}{|c|c|c|c|c|c|c|c|c|}
\hline $\begin{array}{l}\text { A. } \\
\text { Stepniewska2009 }\end{array}$ & प & $\overline{0}$ & [ & पार & & प & Q & प \\
\hline $\begin{array}{l}\text { Auélie } \quad \text { Vallée } \\
2018\end{array}$ & ] & $\square$ & ] & & ] & $\square$ & 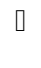 & \\
\hline $\begin{array}{l}\text { Christel } \\
\text { Meuleman2009 }\end{array}$ & ] & प & ] & & प & ] & ] & ] \\
\hline $\begin{array}{l}\text { Christel } \\
\text { Meuleman2014 }\end{array}$ & ] & प & ] & & प & ] & 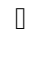 & ] \\
\hline $\begin{array}{l}\text { Emile } \\
2010\end{array}$ & ] & प & ] & प्र & & ] & ] & ] \\
\hline $\begin{array}{l}\text { Gabriele } \\
\text { Centini2016 }\end{array}$ & [ & ૫ & [ & & ૫ & ] & ] & [ \\
\hline $\begin{array}{l}\text { Gabriele } \\
\text { Centini2018 }\end{array}$ & प & $\square$ & ] & & ] & ] & 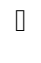 & प \\
\hline $\begin{array}{l}\text { Gernot } \\
\text { Hudelist2018 }\end{array}$ & प & प & ] & & प & ] & 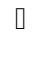 & ] \\
\hline $\begin{array}{l}\text { Horace } \\
\text { Roman2015 }\end{array}$ & [ & [ & [ & & [ & [ & Q & [ \\
\hline Luca Minelli2009 & ] & प & ] & & प & {[} & 0 & ] \\
\hline M.Blanc 2017 & ( & ૫ & ( & & ( & [ & Q & प \\
\hline $\begin{array}{l}\text { Mario } \\
\text { Malzoni2015 }\end{array}$ & प & ૫ & प & & Q & ] & Q & [ \\
\hline $\begin{array}{l}\text { Nicolas } \\
\text { Bourdel2018 }\end{array}$ & ] & प & प & & 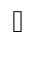 & Q & $\square$ & प \\
\hline $\begin{array}{l}\text { Némie } \quad \text { Marty } \\
2017\end{array}$ & ] & प & ? & & प & ] & 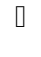 & ] \\
\hline $\begin{array}{l}\text { Simone } \\
\text { Ferrero2009 }\end{array}$ & ] & प & ] & प्र & & ] & ] & ] \\
\hline Yohei Kishi 2016 & (] & ( & (] & & Q & [ & ] & Q \\
\hline
\end{tabular}

Figures

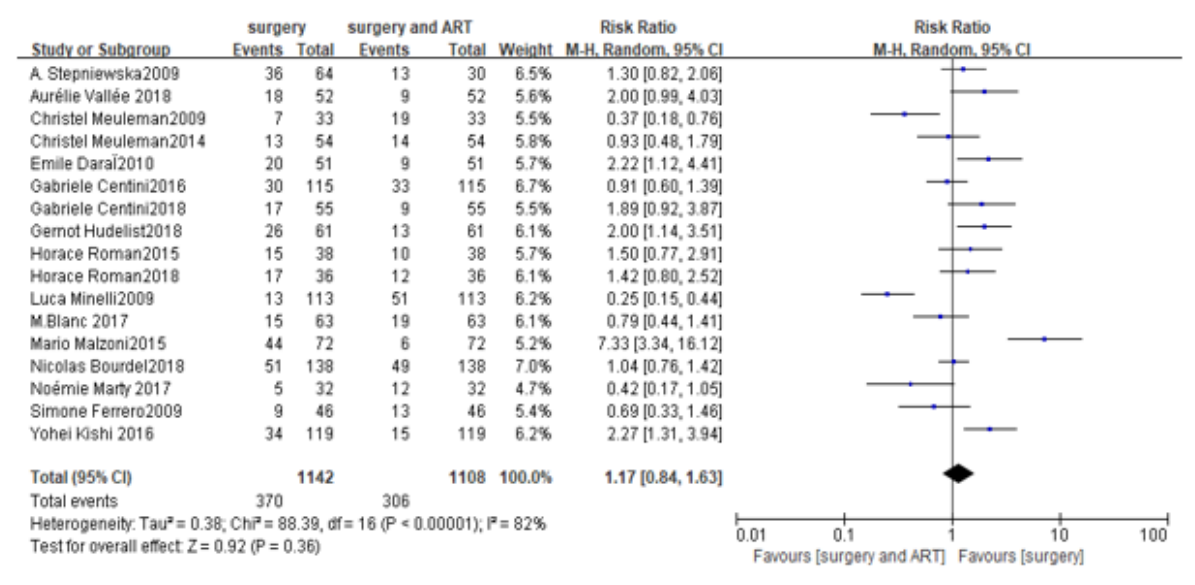

\section{Figure 1}

Forest plot showing the likelihood of clinical pregnancy in women with DIE through different methods . 


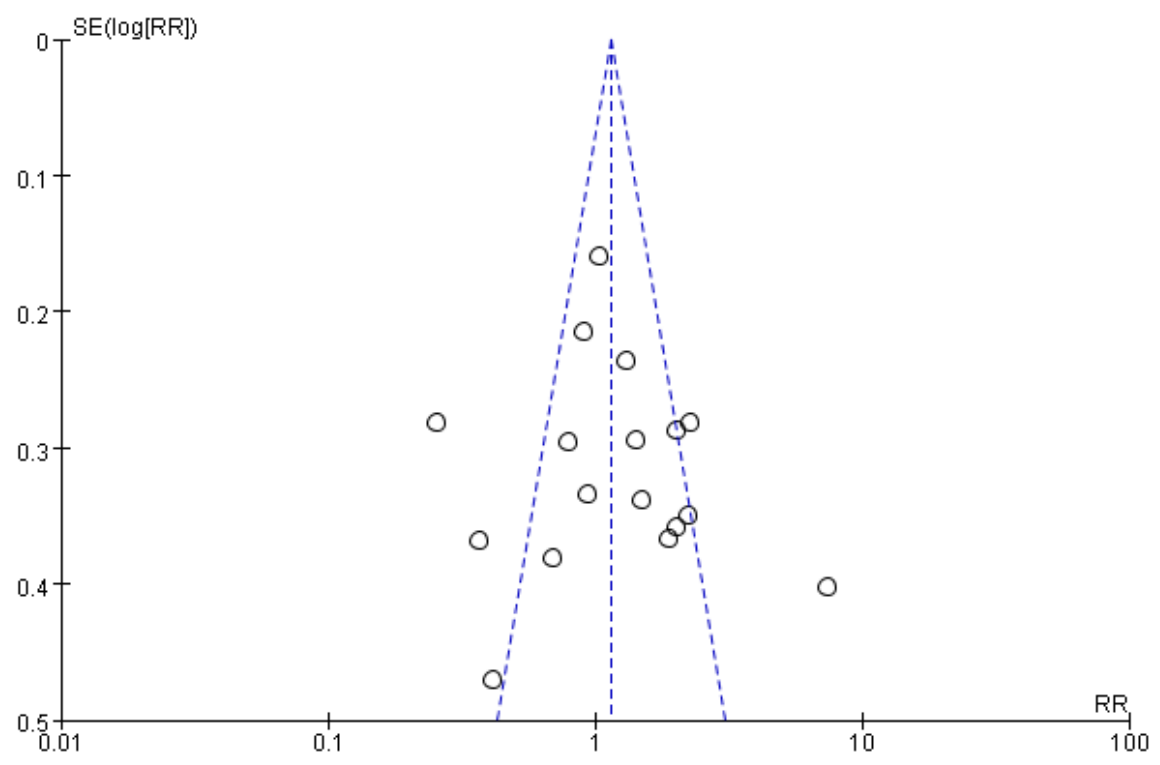

\section{Figure 2}

Funnel plot 17 studies in which the effect of different treatment on the likelihood of clinical pregnancy in women with DIE

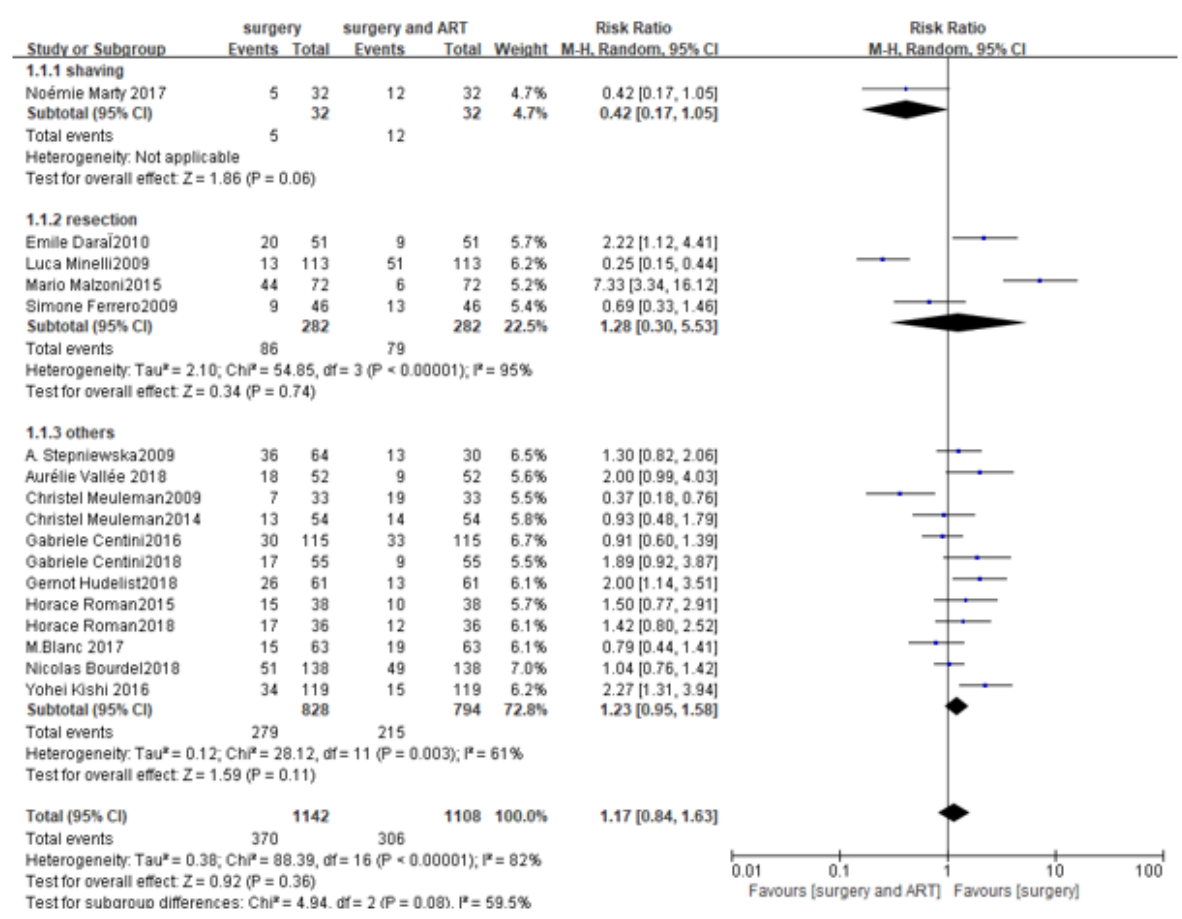

\section{Figure 3}

Forest plot showing the likelihood of clinical pregnancy in women with different surgery methods. 


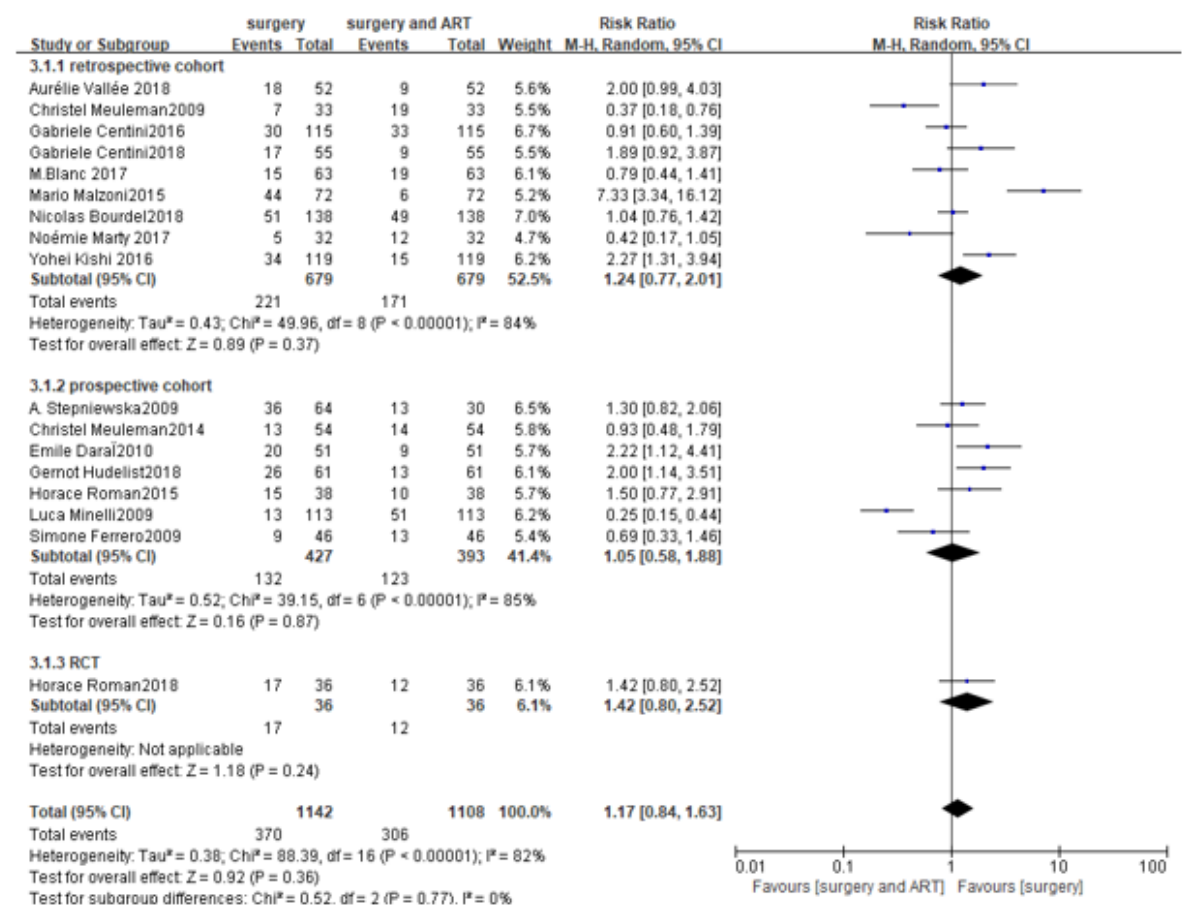

\section{Figure 4}

Forest plot showing the likelihood of clinical pregnancy in women with different study characterics.

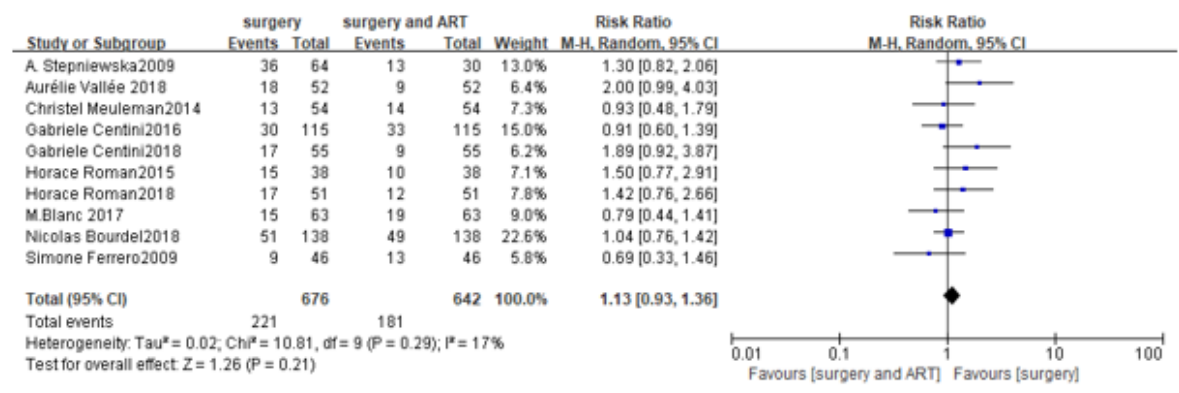

\section{Figure 5}

Forest plot showing the likelihood of clinical pregnancy in women after sensitivity analysis

\section{Supplementary Files}

This is a list of supplementary files associated with this preprint. Click to download.

- PRISMA2009checklist.pdf

- Table2.pdf 